\title{
Farklı Eğim Derecelerindeki Korunan ve Otlatılan Meralarda Bazı Islah Metotlarının Bitki Örtüsü Üzerine Etkileri
}

\author{
Canan ŞEN $^{1} \quad$ Soner GÜNAY ${ }^{2} \quad$ Cengiz KURT ${ }^{3} \quad$ Yahya T. TUNA 4 \\ ${ }^{1}$ Namık Kemal Üniversitesi Ziraat Fakültesi Tarla Bitkileri Bölümü-Tekirdağ \\ ${ }^{2}$ Atatürk Toprak Su Ve Tarımsal Meteoroloji Araştırma Enstitüsü Müdürlüğü -Kırklareli \\ ${ }^{3}$ Trakya Tarımsal Araştırma Enstitüsü Müdürlüğü-Edirne \\ ${ }^{4}$ Namık Kemal Üniversitesi Ziraat Fakültesi Zootekni Bölümü-Tekirdağ \\ $\triangle$ : ctuna@nku.edu.tr
}

Geliş (Received): 02.11.2017

Kabul (Accepted): 15.12.2017

\begin{abstract}
ÖZET: Araştırma, Kırklareli İlinin Koruköy doğal mera alanında 2009-2013 yılları arasında yapılmıştır. Araştırmanın amacı, korunan ve otlatılan meralarda farklı eğim derecelerinde (\% 6-12 ve \% 12-20) gübreleme ve üstten tohumlama uygulamasının kuru ot verimleri, botanik kompozisyon ve toprağı kaplama alanı üzerine etkilerini belirlemektir. Gübreli parsellerden $382.1 \mathrm{~kg} / \mathrm{da}$, tohumlu parsellerden $292.9 \mathrm{~kg} / \mathrm{da}$, doğal parsellerden $180.1 \mathrm{~kg} / \mathrm{da}$ kuru ot verimi elde edilmiştir. Araştırmamızda korunan alanların beş yıllık ortalama kuru ot verimleri $(327.0 \mathrm{~kg} / \mathrm{da})$, otlatılan alanlardan $(243.1 \mathrm{~kg} / \mathrm{da})$ daha yüksek olduğu belirlenmiştir. Gübreleme uygulanan parsellerde buğdaygiller oranı (\%79.1) en yüksek değerde ilk sırayı almış, üstten tohumlama yapılan parseller (\%71.6) ikinci sırada, doğal merada (\%61.2) ise en az seviyede tespit edilmiştir. Diğerleri doğal merada en yüksek(\%27.8)oranda iken, buğdaygillerin tersine gübreli merada (\%13.3) en düşük değerde yer almıştır. Üstten tohumlamada ise bu oran \%19.1 olarak belirlenmiştir. Eğim derecesi yüksek alanlarda diğer familyadan türler oranı daha yüksek olduğu belirlenmiştir. Bitki örtüsünün toprağı kaplama oranları botanik kompozisyon oranları ile benzer değerdedir. Sonuç olarak, gübreleme uygulaması doğal mera vejetasyonlarının kuru ot veriminin arttırılmasında önemli bir uygulamadır. Azotlu gübreleme buğdaygillerin gelişimini teşvik etmektedir. Üstten tohumlama uygulaması bitki örtüsünün toprağı kaplama alanı düşük olan ve yağış rejiminin yüksek olduğu bölgelerde koruma ile önerilebilir. Doğal meralarda bitki örtüsünün botanik kompozisyonu dikkatle izlenmeli ve çoğalıcı ve istila edici türlerin artmaya başlamasıyla hafif ya da orta dereceli otlatmaya geçilmelidir.

Anahtar Kelimeler: Mera, eğim, gübreleme, üstten tohumlama, koruma, otlatma
\end{abstract}

\section{The Effects of Some Improvement Methods on Vegetation in Grazed and Ungrazed Pastures with Different Slopes}

\begin{abstract}
The research was carried out in Koruköy natural pasture area in Kırklareli Province between 2009 and 2013. The aim of the study was to determine the effects of fertilization and top-dressing applications on hay yield, botanical composition and canopy cover in grazed and ungrazed pastures area at different slopes (6-12\% and 12-20\%). Hay yields obtained in the study were $382.1 \mathrm{~kg} / \mathrm{da}$ for fertilized plots, $292.9 \mathrm{~kg} / \mathrm{da}$ for oversowing plots and $180.1 \mathrm{~kg} / \mathrm{da}$ for natural plots. In our study, it was determined that the ungrazed areas had a higher average dry hay yield for five years $(327.0 \mathrm{~kg} / \mathrm{da})$ compared to that in grazed areas $(243.1 \mathrm{~kg} / \mathrm{da})$. The ratio in grasses $(79.1 \%)$ was the highest in the fertilized plots, this was followed by the oversowing plots $(71.6 \%)$ and the natural plots yielded the lowest values $(61.2 \%)$. Other plant families yielded the highest ratio $(27.8 \%)$ in the natural pasture whereas, unlike grasses, had the lowest value (13.3\%) in the fertilized pasture. The ratio determined in the oversowing application was $19.1 \%$. The ratios obtained in other families in areas with higher slopes were higher. Canopy cover ratios were similar to botanical composition ratios. In conclusion, nitrogen fertilization is important in increasing the hay yield in natural pasture vegetation. Nitrogen promotes the growth of grasses. Oversowing application can be recommended in regions with low soil surface covering areas and in regions with high precipitation regime in addition to ungrazing. Botanical composition of the vegetation should be monitored and mild or moderate grazing should be initiated if propagating and invading species start to develop in natural pastures.

Keywords: Pasture, slope, oversowing, ungrazed, grazed
\end{abstract}

\section{GİRIŞ}

Çayır ve meralar, bir ülkenin en önemli doğal kaynaklarındandır. Bu alanlar hayvanların ihtiyacı olan kaba yemin en ucuz karşılandığı yer olma özelliğinin yanında biyolojik çeşitlilik yaratması, toprak üzerinde kalkan görevi görerek onu erozyona karşı koruması gibi fonksiyonlara sahiptirler. Meralar, konum olarak tarlaların üst sınırı ile ormanların alt sınırları arasındaki eğimli (\% 12 - 30) ve engebeli alanlarda oluştuğu (Altın ve ark., 2005) için erozyon zararı daha fazla olabilmektedir. Araştırmanın yapıldığı, Kırklareli ilinde toplam 32.9 ha'lık bir alanı oluşturan çayır ve mera arazilerinin hemen hepsi az veya çok problemlidir (Altın ve Tuna 2001). Engebeli alanlarda toprağ yerinde tutmanın tek yolu ise buraları bitki örtüleri ile kaplamaktan geçer. Bitki örtüsünün oluşturulmasında da mevcut olan durumun bilinme zorunluluğu vardır. Bu çalışmanın amacı; mera ıslah yöntemleri ile birlikte farklı eğimlerde otlatılan ya da korunan meralardaki bitki örtüsünün niteliğinin belirlenmesidir. $\mathrm{Bu}$ amaçla meralarda en çok kullanılan ve en etkili 1slah yöntemlerin başında gübreleme ve üstten tohumlama 
gelmektedir. Tükel ve Hatipoğlu (1987), korunan bir merada yaptıkları çalışmalarında, gübresiz parsellerdeki kuru ot veriminin yıllara göre $146.3 \mathrm{~kg} / \mathrm{da}$ ile 272.3 $\mathrm{kg} / \mathrm{da}$ arasında değiştiğini, verimin çoğunluğunu buğdaygillerin oluşturduğunu, azot gübresi uygulanan parsellerde ise kuru ot veriminin $148 \mathrm{~kg} / \mathrm{da}$ ile 539.5 $\mathrm{kg} / \mathrm{da}$ arasında değiştiğini bildirmişlerdir. Krumov ve Malinov (1989), aşırı derecede erozyona uğramış mera topraklarında, doğal mera bitkilerinin kendi kendini yenilemesi ve erozyona karşı direncini belirlemek amacıyla yaptıkları çalışmalarında, en iyi sonucu 3 yıl otlatılmayan parselden almışlardır. Gübrelemenin toprak erozyonuna karşı etkisinin en iyi görüldüğü parselin devamlı otlatılan parsel olduğunu tespit etmişlerdir. Dağdeviren ve Erdoğan (1991), \% 12 - 15 eğimli doğal mera alanında, suni tohumlama + gübreleme ile gübreleme konularının önerilebileceğini, Oran ve Yakar (1992), \% 12 - 32 eğimli bir merada, koruma altına aldıkları merada iki yılda bir azotlu ve fosforlu gübreleme yaptıklarını ve kapasitelerine göre iki yılda bir otlatılarak iyi bir toprak örtüsünün sağlandığını belirtmişlerdir. Volosin ve ark. (2000), üstten tohumlama yaptıkları bir meraya farklı gübre dozlarını uygulamışlar ve en düşük kuru madde verimi gübresiz parsellerde elde edilirken, en yüksek kuru madde verimi $18 \mathrm{~kg} /$ da $\mathrm{N}$ uygulamasında saptanmıştır.

\section{MATERYAL ve YÖNTEM}

Araştırma, Kırklareli merkeze bağlı Koruköy merasında, \% $6-12$ ve $\% 12-20$ oranındaki 2 farklı eğim derecesinde korunan ve otlatılan alanlarda yürütülmüştür. Merada bulunan vejetasyonun zenginleştirmesi için çok yıllık baklagil ve buğdaygil yem bitkilerinden oluşturulan bir karışım kullanılarak ve toprak işlenmeden, kazık (çapa) ayaklı mibzer ile üstten tohumlama yapılmıştır. Belirlenen parseller için uygulanan bu karışım; Medicago sativa L., Onobrychis sativa L., Lolium perenne L., Dactylis glomerata L., ve Festuca arundinacea L. türlerinden oluşmaktadır. Kırklareli'nde yıllık ortalama sıcaklık $13.0{ }^{\circ} \mathrm{C}$ 'dir.

Çizelge 1. Kırklareli İli meteorolojik verileri(yağış:mm)

\begin{tabular}{|c|c|c|c|c|c|c|c|c|c|c|c|}
\hline & & & & & & Yillar & & & & & \\
\hline Aylar & 2009 & 2010 & 2011 & 2012 & 2013 & Aylar & 2009 & 2010 & 2011 & 2012 & 2013 \\
\hline Ekim & 8.6 & 120.4 & 62.2 & 71.8 & 216.6 & Nisan & 30.8 & 49.0 & 51.6 & 47.8 & 15.6 \\
\hline Kasim & 5.2 & 51.8 & 59.8 & 2.8 & 14.4 & Mayıs & 34.0 & 11.2 & 31.6 & 198.8 & 34.4 \\
\hline Aralık & 16.6 & 149.4 & 6.8 & 106.6 & 115.8 & $\begin{array}{c}\text { Hazira } \\
n\end{array}$ & 28.6 & 90.6 & 22.4 & 3.6 & 127.2 \\
\hline Ocak & $\begin{array}{c}101 . \\
0\end{array}$ & 89.4 & 40.2 & 120.0 & 110.4 & $\begin{array}{c}\text { Temm } \\
\text { uz }\end{array}$ & 34.2 & 113.0 & 46.0 & 26.4 & 29.8 \\
\hline Şubat & $\begin{array}{c}192 . \\
8\end{array}$ & 166.8 & 13.0 & 10.2 & 90.2 & $\begin{array}{l}\text { Ağusto } \\
\text { S }\end{array}$ & 0.6 & 0.0 & 8.2 & 0.2 & 0.2 \\
\hline Mart & 83.8 & 69.0 & 26.8 & 9.4 & 47.8 & Eylül & 67.4 & 8.8 & 34.6 & 11.6 & 11.4 \\
\hline Toplam & & & & & & & 603.6 & 919.4 & 403.2 & 609.2 & 813.8 \\
\hline
\end{tabular}

Araştırmada her yıl merada hakim türlerin çiçeklendiği mayıs ve haziran aylarında biçim yapılmış, kuru ağırlıklarının yanı sıra otlatma öncesi dönemlerde Şerit (transekt) metodu ile vejetasyonun botanik kompozisyon toprağı kaplama oranları belirlenmiştir. Denemenin birinci yılında parsellere kompoze gübre ve deneme süresince her yıl aynı parsellere ilkbaharda 20 $\mathrm{kg} / \mathrm{da}$ amonyum Nitrat gübresi verilmiştir. Meranın toprak özellikleri $\mathrm{pH} 5.4$, organik madde 1.4 $\mathrm{P}_{2} \mathrm{O}_{5}(\mathrm{~kg} / \mathrm{da}) \quad 1.9$ ve $\mathrm{K}_{2} \mathrm{O}(\mathrm{kg} / \mathrm{da}) \quad 41.6$ olarak belirlenmiştir.

\section{BULGULAR ve TARTIŞMA}

Uygulanan 1slah metotları (gübreleme, üstten tohumlama)ve doğal mera kuru ot verimi açısından incelendiğinde gübreleme uygulamasının diğer konulara göre daha avantajlı sonuçlar verdiği görülmüştür. Kuru ot verimlerinde y1llar, uygulamalar, eğim ve mera durumu bakımdan istatistiksel olarak önemli farklılıklar bulunmuştur $(\mathrm{P}<0.01)$. Gübreli parsellerden yıllar ortalamas1 olarak $382.1 \mathrm{~kg} / \mathrm{da}$, tohumlu parsellerden $292.9 \mathrm{~kg} / \mathrm{da}$, doğal mera parsellerinden $180.1 \mathrm{~kg} / \mathrm{da}$ kuru ot verimi elde edilmiştir. Araştırmamızda korunan alanların beş yıllık ortalama kuru ot verimleri (327.0 $\mathrm{kg} / \mathrm{da}$ )otlatılan alanlardan(243.1 kg/da) daha yüksek olduğu belirlenmiştir. Yıllar itibari ile en yüksek kuru ot verimi 2012 yılında $(366.9 \mathrm{~kg} / \mathrm{da})$ elde edilmiştir. 2012 y1lında bitkilerin gelişme dönemi olan mart-mayıs ayları arasındaki yağış miktarının diğer yıllara göre yüksek olması (Çizelge 1) kuru ot verimlerini olumlu yönde etkilemiştir. Bir başka açıdan verileri ele alacak olursak; gübreli ve üstten tohumlamalı parsellerde \%12-20 eğime sahip alanlarda \%6-12 eğimli alanlara göre kuru ot verimlerinin daha yüksek olduğu ve doğal mera parsellerinde eğim bakımından aynı grup içerisinde yer aldığı tespit edilmiştir. Yıllar ortalaması olarak iki eğim derecesinde de en yüksek kuru ot verimi korunan mera alanlarından alınmıştır (Çizelge 2). Meranın doğal botanik kompozisyonunu buğdaygillerden Festuca ovina, Dactylis glomerata, Chrysopogon gryllus, Vulpia ciliata, baklagillerden Trifolium campestre, Vicia sativa, diğerlerini Thymus longicaulis, Sanguisorba minor gibi türler oluşmaktadır. 
Çizelge 2. Meranın kuru ot verimleri $(\mathrm{kg} / \mathrm{da})$

\begin{tabular}{|c|c|c|c|c|c|c|c|c|c|}
\hline \multirow[b]{2}{*}{ Uygulama } & \multirow{3}{*}{$\begin{array}{c}\text { Ĕgim } \\
(\%) \\
6-12 \\
\end{array}$} & \multirow{3}{*}{$\begin{array}{c}\text { Mera } \\
\text { Durumu } \\
\mathrm{K}\end{array}$} & \multicolumn{7}{|c|}{ Kuru Ot Verimleri (kg/da) } \\
\hline & & & 2009 & 2010 & 2011 & 2012 & 2013 & Ort. & Ĕgim Ort \\
\hline \multirow{4}{*}{ Gübreli } & & & 495.9 & 337.7 & 237.9 & 390.3 & 305.3 & 353.4 & \multirow{2}{*}{$336.7 b$} \\
\hline & & $\mathrm{O}$ & 380.5 & 309.3 & 239.0 & 357.0 & 314.6 & 320.1 & \\
\hline & $12-20$ & $\mathrm{~K}$ & 496.3 & 552.3 & 386.0 & 580.0 & 433.6 & 489.6 & \multirow{2}{*}{$427.5 \mathrm{a}$} \\
\hline & & $\mathrm{O}$ & 379.3 & 367.0 & 364.3 & 405.3 & 311.6 & 365.5 & \\
\hline Ort. & & & 438.0 & 391.5 & 306.8 & 433.1 & 341.3 & $382.1 \mathrm{a}$ & \\
\hline \multirow{4}{*}{ Tohumlu } & $\begin{array}{c}6- \\
12\end{array}$ & $\mathrm{~K}$ & 370.2 & 244.7 & 224.0 & 423.3 & 309.6 & 314.4 & \multirow[t]{2}{*}{$277.1 \mathrm{c}$} \\
\hline & & $\mathrm{O}$ & 229.6 & 167.3 & 199.6 & 368.6 & 234.0 & 239.8 & \\
\hline & $12-20$ & $\mathrm{~K}$ & 330.1 & 269.0 & 242.3 & 514.3 & 409.3 & 353.0 & \multirow{2}{*}{$308.8 b c$} \\
\hline & & $\mathrm{O}$ & 307.2 & 179.0 & 299.6 & 286.0 & 251.0 & 264.5 & \\
\hline Ort. & & & 309.3 & 215 & 241.4 & 398.0 & 301 & $292.9 b$ & \\
\hline \multirow{4}{*}{ Doğal } & $6-12$ & K & 155.8 & 116.3 & 195.3 & 335.6 & 266.3 & 213.8 & \multirow{2}{*}{$170.7 \mathrm{~d}$} \\
\hline & & $\mathrm{O}$ & 137.6 & 83.4 & 120.6 & 175.6 & 121.0 & 127.6 & \\
\hline & $12-20$ & $\mathrm{~K}$ & 132.8 & 109.0 & 157.3 & 389.0 & 400.6 & 237.7 & \multirow{2}{*}{$189.5 \mathrm{~d}$} \\
\hline & & $\mathrm{O}$ & 128.9 & 107.0 & 157.0 & 178.3 & 135.0 & 141.2 & \\
\hline Ort. & & & 138.8 & 103.9 & 157.5 & 269.6 & 230.7 & $180.1 \mathrm{c}$ & \\
\hline Yillar Ort & & & $295.3 b$ & $236.8 \mathrm{c}$ & $235.2 \mathrm{c}$ & $366.9 \mathrm{a}$ & $291.0 b$ & 285.1 & \\
\hline Korunan & & & $330.2 b$ & $271.5 \mathrm{c}$ & $240.5 d$ & $438.7 \mathrm{a}$ & $354.1 \mathrm{~b}$ & $327.0 \mathrm{a}$ & \\
\hline Otlatılan & & & $260.5 \mathrm{ab}$ & $202.1 \mathrm{c}$ & $230.0 \mathrm{~b}$ & $295.1 \mathrm{a}$ & $227.8 b$ & $243.1 b$ & \\
\hline F Değer & & & Y1l: 13. & .mera du & :39.9** & $42,6^{* *}, \mathrm{e}$ & $2.5^{* *} . \mathrm{y} 1$ & adurumu & \\
\hline
\end{tabular}

K:Korunan O:Otlanan,uyg:uygulama, Aynı satır ve sütunda farklı harf taşıyan ortalamalar arasında farklılık vardır, $* * \mathrm{P}<0.01, * \mathrm{P}<0.05$

Çizelge 3. Meranın botanik kompozisyon oranı(\%)

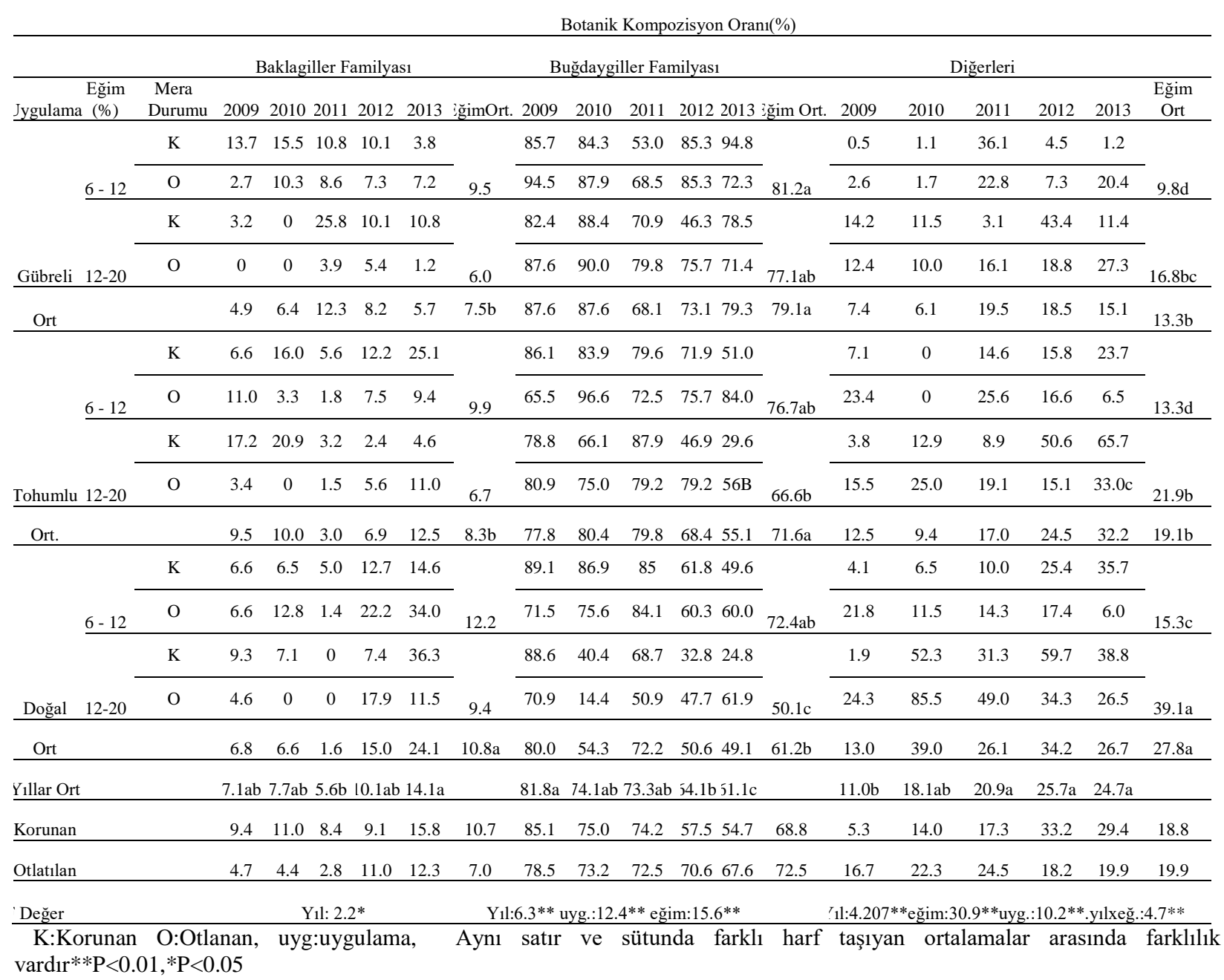


Çizelge 4. Mera bitki örtüsünün toprağı kaplama oranı (\%)

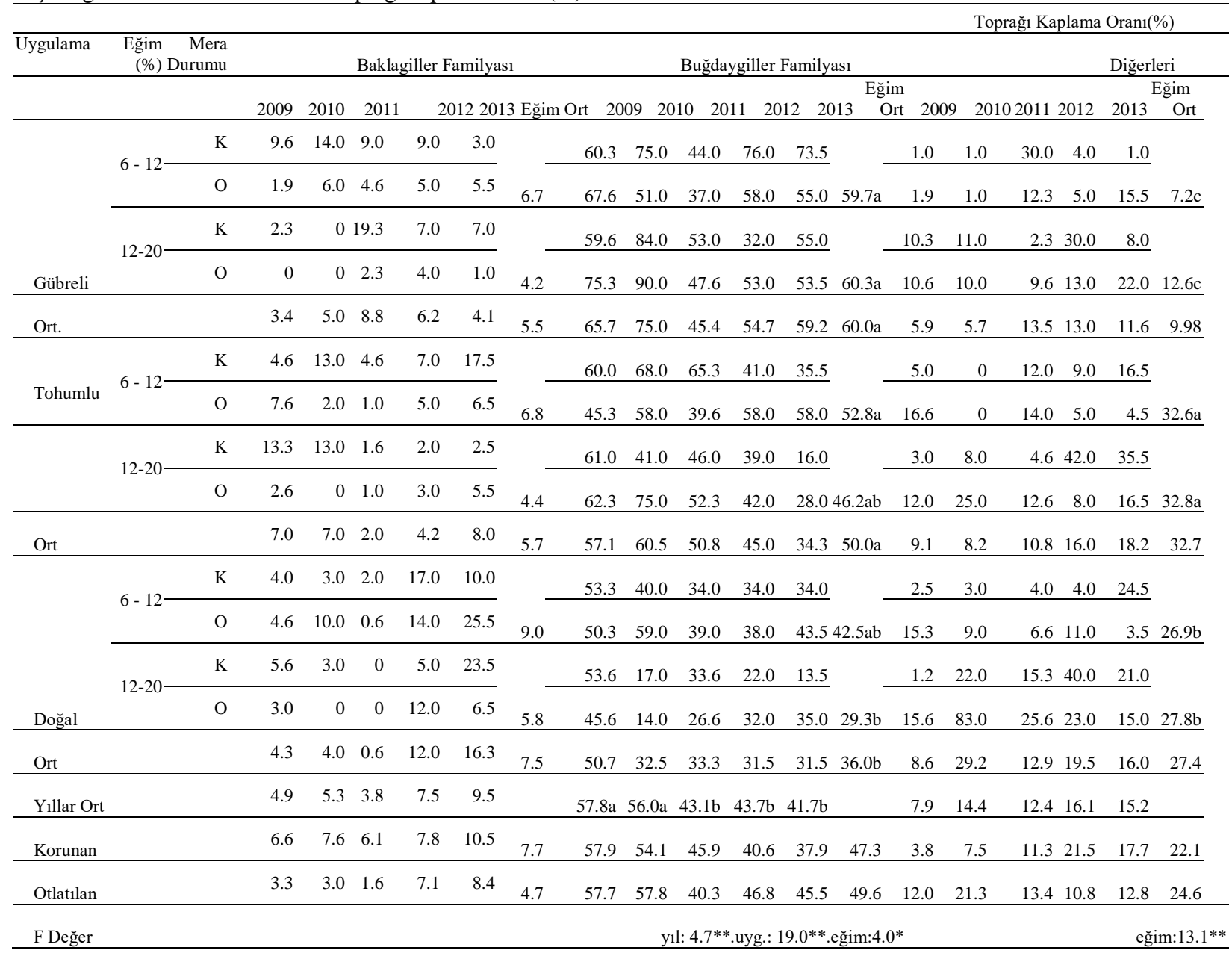

K:KorunanO:Otlanan,uyg

Araştırma alanının botanik kompozisyonunun belirlenmesi amacıyla yapılan ölçümler sonucunda, yılların etkisi baklagiller, buğdaygiller ve diğer familyadan türlerde istatistiksel olarak farklılıklar oluşturmuştur $(\mathrm{P}<0.01, \mathrm{P}<0.05)$. En yüksek baklagil oranına denemenin son yılında(\%14.1) ulaşılmıştır. Gübreleme uygulanan parsellerde buğdaygiller oranı(\%79.1) en yüksek değerde ilk sırayı almış, üstten tohumlama yapılan parseller (\%71.6)ikinci sırada, doğal merada (\%61.2) ise en az seviyede tespit edilmiştir. Diğerleri doğal merada en yüksek(\%27.8)oranda iken, buğdaygillerin tersine gübreli merada (\%13.3) en düşük değerde yer almıştır. Üstten tohumlamada ise bu oran \%19.1 olarak belirlenmiştir. Eğim bakımından sonuçlarımızı irdelediğimizde; eğimli meralarda (\%12$20)$, diğerleri oranının az eğimli (\%6-12) 'ye göre daha yüksek olduğu belirlenmiştir ve istatistiksel olarak önemli bulunmuştur $(\mathrm{P}<0.01)($ Çizelge 3$)$. Bu durum yörede kötü kullanımlar sonucu verimliliklerini yitiren ancak botanik kompozisyondaki tahribatın ileri boyutlarda olmadığ 1 meraların 1slahında, gübrelemenin en uygun yöntemlerden biri olduğunu göstermektedir. Benzer sonuçlar birçok araştırıcı tarafindan yürütülen denemelerin verilerinde de görülebilir (Altın ve Tuna, 1991; Çomaklı ve ark., 2005; Altın ve ark., 2007). Ülkemizde yapılan mera botanik kompozisyonu ve bitki kaplama alanları çalışmalarında en yüksek değerler buğdaygiller familyasına aittir (Gökkuş, 1984; Koç ve Gökkuş, 1996; Altın ve ark, 2007). Buğdaygiller yumak ve vejetatif organları ile baskın duruma geçerek Diğerlerinin gelişimini engellediğini söyleyebiliriz. Bitki örtüsü toprak yüzeyinde yeteri oranda bir yayılım gerçekleştirirse erozyonu azaltmada önemli bir rol oynamaktadır. Baklagiller familyasının toprağı kaplama oranı denemenin son yılında en yüksek değere (\%9.5) ulaşmıştır (Çizelge 4). Buğdaygillerin toprağı kaplama oranları denemenin ilk yılından sonra botanik kompozisyonda olduğu gibi azalma eğiliminde olduğu belirlenmiştir. Doğal merada ve üstten tohumlama parsellerindeki buğdaygillerin yıllar bazında azalması ile meydana gelmiştir. Burada gübrelemenin azalmada bir etkisi olmamıştır. Sebep diğer familya oranlarının daha fazla artması olabilir. Gübreleme uygulamasında buğdaygillerin kaplaması en yüksek değerde (\%60.0) ilk sırayı almış, üstten tohumlama ikinci sırada (\%50.0), doğal merada buğdaygillerin kaplama oranı en az seviyede (\%36.0) tespit edilmiştir (Çizelge 4). Bölgede yapılan araştırmalarda(Altın ve ark., 2005; Altın ve ark., 2007), gübreleme uygulamasının buğdaygiller ve baklagiller oranını artırdığ1, diğerleri oranını azalttığ tespit edilmiştir. 


\section{SONUC}

Gübreleme ve koruma doğal mera vejetasyonlarının kuru ot veriminin arttırılmasında önemli bir uygulamadır. Azotlu gübreleme buğdaygillerin gelişimini teşvik etmektedir. Ancak baklagiller oranının arttırılması için koruma ve kompoze gübre desteğinin de yapılmasını önerebiliriz. Üstten tohumlama uygulaması bitki örtüsünün toprağı kaplama alanı düşük olan ve yağış rejiminin yüksek olduğu bölgelerde koruma ile önerilebilir. Doğal meralarda bitki örtüsünün botanik kompozisyonu dikkatle izlenmeli ve çoğalıcı ve istila edici türlerin artmaya başlamasıyla hafif ya da orta dereceli otlatmaya geçilmelidir.

\section{TESEKKKÜR}

$\mathrm{Bu}$ çalışma TAGEM-TA-071102002 No'lu proje kapsamında desteklenmiştir.

\section{KAYNAKLAR}

Altın M, Tuna M 1991. Değişik sslah yöntemlerinin Banarlı köyü doğal merasının verim ve vejetasyonu üzerindeki etkileri. Türkiye 2. Çayır Mera ve Yem Bitkileri Kongresi, 28-31 Mayıs 1991, İzmir, 95-105 s.

Altın M, Tuna C 2001. Trakya meralarının bazı özellikleri ile yöre tarımındaki önemi. Türkiye 4 . Tarla Bitkileri Kongresi, Tekirdağ.

Altın M. Tuna C, Nizam İ, Ateş E 2005. Pirinççi köyü meraları dolgu alanların bitkilendirme uygulamaları. VI. Tarla Bitkileri Kongresi. Antalya, $1157-1162 \mathrm{~s}$.

Altın M, Tuna C, Gür M 2007. Bir ıslah çalışmasının doğal mera ekosisteminin vejetasyonu üzerindeki bazı etkileri. Türkiye VII. Tarla Bitkileri Kongresi, 25-27 Haziran, Erzurum.

Çomaklı B, Güven M, Koç A, Menteşe Ö, Bakoğlu A, Bilgili A 2005. Azot, fosfor ve kükürtle gübrelemenin Ardahan meralarının verim ve tür kompozisyonuna etkisi. Türkiye VI. Tarla Bitkileri Kongresi, 5-9 Eylül, Antalya, Cilt II, 757-761 s.

Dağdeviren İ, Erdoğan İ 1993. GAP Bölgesi Şanlıurfa Yöresinde bazı mera iyileştirme yöntemlerinin toprak ve su korunumuna etkisinin saptanması, Köy Hizmetleri Araştırma Enstitüsü Yayınları, Şanlıurfa.

Gökkuş A 1984. Değişik 1slah yöntemleri uygulanan Erzurum tabii meralarının kuru ot ve ham protein verimleri ile botanik kompozisyonları üzerinde araştırmalar (Yayınlanmamış Doktora Tezi), Atatürk Üniversitesi, Ziraat Fakültesi, Erzurum.

Koç A, Gökkuş A 1996. Palandöken dağlarında kayak pisti olarak kullanılan ve nispeten korunan mera ile otlatılan meranın bitki örtülerinin karşılaştırılması. Türkiye 3. Çayır Mera ve Yembitkileri Kongresi, 17-19 Haziran, Erzurum, 162-170 s.

Krumov V, Malinov İ 1989. Aşırı derecede erozyona uğramış mera topraklarında, doğal mera bitkilerinin kendi kendini yenilemesi ve erozyona karşı direnci. Soil Science and Agrochemistry, Vol. XXIV, No 5, Sofia.

Oran N, Yakar M 1992. Gediz Havzasında bazı mera iyileştirme yöntemlerinin toprak ve su korunumuna etkilerinin saptanması. Köy Hizmetleri Araştırma Enstitüsü Yayınları. Menemen, İzmir.

Tükel T, Hatipoğlu R 1987. Çukurova Koşullarında farklı azot dozlarının tüylü sakalotu $(H$. hirta $L$.Stapf )'nun baskın olduğu doğal bir meranın verim ve botanik kompozisyonuna etkisi üzerine bir araştırma. Ç.Ü. Ziraat Fakültesi Dergisi, Sayı: 1, Adana.

Volosin J, Jezikova O, Horvath C, Majernik F, Rovas M, Feriencikova D, Gaborcik N, Ondrasek L, Uhliarova E, Zimkova M 2000. Ecosystem development in permanent, oversown and temporary grassland of the Pohronsky Inovec Region. Grassland Ecology V. Proceeding of the 5th Ecological Conference, Banska Bystrica, Slovakia, 23-25 November, 100-116 pp. 